\title{
Increased Intrahepatic Expression of Immune Checkpoint Molecules in Autoimmune Liver Disease
}

\author{
Zuzana Macek Jilkova 1,2,3,4,*(D), Marie Noelle Hilleret ${ }^{3,4}$, Theophile Gerster ${ }^{3,4}$, Nathalie Sturm ${ }^{1,5}$, \\ Marion Mercey-Ressejac 1,2,3, Jean-Pierre Zarski 1,2,3, Vincent Leroy ${ }^{3}$, Patrice N. Marche ${ }^{1,2} \mathbb{D}$, \\ Charlotte Costentin ${ }^{1,2,3,4}$ and Thomas Decaens $1,2,3,4, *$ (D)
}

1 Université Grenoble Alpes, 38000 Grenoble, France; NSturm@chu-grenoble.fr (N.S.); mressejac@chu-grenoble.fr (M.M.-R.); jpzarski@chu-grenoble.fr (J.-P.Z.); patrice.marche@univ-grenoble-alpes.fr (P.N.M.); CCostentin@chu-grenoble.fr (C.C.)

2 Research Center Inserm U1209, Institute for Advanced Biosciences, CNRS UMR5309, 38700 La Tronche, France

3 Service d'Hépato-Gastroentérologie, Pôle Digidune, CHU Grenoble Alpes, 38700 La Tronche, France; MNHilleret@chu-grenoble.fr (M.N.H.); tgerster@chu-grenoble.fr (T.G.); vincent.leroy2@aphp.fr (V.L.)

4 Reference Center for Inflammatory Biliary Diseases and Autoimmune Hepatitis (MIVB-H), French Network for Rare Liver Diseases in Children and Adults (FILFOIE), 75012 Paris, France

5 Service d'Anatomo-Pathologie, Pôle de Biologie, CHU Grenoble Alpes, 38700 La Tronche, France

* Correspondence: zmacekjilkova@chu-grenoble.fr (Z.M.J.); tdecaens@chu-grenoble.fr (T.D.)

check for

updates

Citation: Macek Jilkova, Z.; Hilleret, M.N.; Gerster, T.; Sturm, N.;

Mercey-Ressejac, M.; Zarski, J.-P.;

Leroy, V.; Marche, P.N.; Costentin, C.;

Decaens, T. Increased Intrahepatic

Expression of Immune Checkpoint

Molecules in Autoimmune Liver

Disease. Cells 2021, 10, 2671. https:/ /

doi.org/10.3390/cells10102671

Academic Editor: Yasu-Taka Azuma

Received: 9 August 2021

Accepted: 1 October 2021

Published: 6 October 2021

Publisher's Note: MDPI stays neutral with regard to jurisdictional claims in published maps and institutional affiliations.

Copyright: (c) 2021 by the authors. Licensee MDPI, Basel, Switzerland. This article is an open access article distributed under the terms and conditions of the Creative Commons Attribution (CC BY) license (https:// creativecommons.org/licenses/by/ $4.0 /)$.

\begin{abstract}
Immune checkpoint molecules (ICM) are critical in maintaining immunologic homeostasis and participate in preventing or promoting autoimmune disease development. Exploring a large panel of intrahepatic inhibitory and stimulatory ICM is necessary for drawing a general picture of the immune alterations in autoimmune hepatitis $(\mathrm{AIH})$. Here, we performed a multiparametric analysis of ICM, including PD-1, TIM3, LAG3, CTLA-4, OX40 and 4-1BB, and we determined their expression on intrahepatic lymphocyte subsets in untreated and in treated patients with $\mathrm{AIH}$ in comparison to normal liver tissue. AIH patient-derived liver tissue revealed the overexpression of ICM, mainly PD-1 and 4-1BB, as well as the strong correlation between PD- $1^{+} \mathrm{CD} 8^{+} \mathrm{T}$-cell abundance and severity of AIH (alanine transaminase and aspartate transaminase levels). Our results show that the ICM play an important role in the loss of immune homeostasis in the liver, providing an attractive approach to investigate their role as targets for effective therapeutic interventions.
\end{abstract}

Keywords: autoimmune liver disease; autoimmune hepatitis; immune checkpoint molecules; PD-1; 4-1BB

\section{Introduction}

Autoimmune liver diseases (AILD) are rare diseases characterised by immune-mediated hepatic injury. AILD have been mainly categorised into: (i) autoimmune hepatitis (AIH), (ii) primary sclerosing cholangitis (PSC) and (iii) primary biliary cholangitis (PBC). In $\mathrm{AIH}$, the autoimmune injury targets mostly the hepatocytes, while in PSC the mediumsized intra- and extrahepatic bile ducts and in PBC interlobular bile ducts are affected [1]. Despite different patterns of inflammation, clinical phenotype, and outcomes, AIH, PSC and $\mathrm{PBC}$ are frequently grouped due to similarities in immunological markers, symptoms and treatment options. The incidence of AILD is increasing in certain countries [2-4]. Currently, the reported incidence rate of AIH ranges from 1 to 2.5 per 100,000 individuals in Europe. PBC and PSC are more common in northern than in southern Europe countries, and the reported incidence ranges from approximately 0.5 to 2.6 cases per 100,000 personyears [5-8].

AILD represent complex disorders characterized by an abnormal reactivity of the immune system against self-antigens. Compared to other forms of AILD, the immune alterations associated with $\mathrm{AIH}$ are relatively well described, but mostly at the peripheral blood level. AIH is characterized by loss of self-tolerance, which results from autoreactive $\mathrm{CD}^{+}$and $\mathrm{CD}^{+} \mathrm{T}$ cells and $\mathrm{B}$ cells and their abnormal activation and proliferation. T-cell 
mediated immune attack, which occurs during AIH, is caused by CD4+ T cells that secrete a range of pro-inflammatory cytokines, resulting in the recruitment and activation of other immune cells, and by cytotoxic CD8+ T cells that directly damage liver tissues $[9,10]$. Today, a majority of patients with AIH respond to standard immunosuppressive therapy with azathioprine and steroids. Still, insufficient response to standard therapy or serious side effects in 10-20\% of AIH patients may require treatment changes [11]. The inflammatory process in AIH may be ameliorated and the immune tolerance could be potentially restored by targeting specific molecules involved in this abnormal autoimmune response.

Immune checkpoint molecules (ICM) are critical in maintaining immunologic homeostasis and participate in preventing or promoting autoimmune disease development. Mounting evidence demonstrates that impaired PD-1/PD-L1 function plays an important role in a variety of autoimmune diseases (as reviewed in [12,13]). In fact, PD-1, expressed primarily by T cells, directly inhibits T-cell proliferation and T-cell effector functionssuch as IFN-gamma production and cytotoxic activity - upon the ligation. Thus, this critical checkpoint counteracts immune stimulatory signals and limits cytotoxic $\mathrm{T}$ cells from tissue destruction. However, in autoimmune diseases, the PD-1/PD-L1 checkpoint pathway fails to stop autoimmune injury. Instead, $\mathrm{PD}-1^{+}$cells infiltrate tissues, and this infiltration may escalate with disease progression, as has been shown in autoimmune encephalomyelitis [14].

In recent years, a growing number of new ICM have been discovered, and their implication in the pathogenesis of autoimmune diseases is currently investigated [15]. Exploring additional inhibitory and stimulatory ICM is necessary for drawing a general picture of the immune alterations in AIH. The intrahepatic expressions of different ICM in AIH were never reported. Here, we provide an exhaustive multiparametric analysis of immunecheckpoint expression on intrahepatic lymphocyte subsets in untreated and treated AIH in comparison to normal liver tissue showing a prominent link with liver pathology.

\section{Materials and Methods}

\subsection{Patients and Liver Biopsy Processing}

This study included 26 patients, who were enrolled between 2017-2021 either at diagnosis prior to any treatment initiation, or during clinical follow-up (Department of Gastroenterology and Hepatology, CHU Grenoble-Alpes). Detailed patient characteristics have been recorded as shown in Table 1. The AIH cohort consists of groups of AIH untreated $(n=11)$ and AIH during treatment $(n=5)$. AIH untreated patients had undergone liver biopsy as part of AIH diagnosis. AIH treated patients had undergone liver biopsy as part of medical follow-up to justify possible treatment withdrawal. The mean time between start of treatment and liver biopsy in group of AIH treated was $29.2 \pm 8.6$ months. The "Normal" control group includes liver biopsies from patients with suspected non-alcoholic fatty liver disease (NAFLD) where NAFLD or any other diagnosis was not confirmed (liver steatosis $<5 \%$ ). Liver biopsies were divided into two parts; one part was used for histological examination, assessed by experienced liver pathologists, whereas the other part was processed within one hour following the clinical biopsy to conduct extensive phenotypic immunological analyses. The diagnosis of AIH was based on clinical (elevated alanine transaminase (ALT), aspartate transaminase (AST), etc.), immunological (positive smooth muscle antibody (SMA) and/or antinuclear antibody (ANA), etc.) and histological parameters (histological features compatible with AIH). All patients with PSC or PBC diagnosis were excluded. The study was performed in accordance with the Declaration of Helsinki and the French legislation based on local sample collection (DC-2014-2295), and all participants provided written informed consent. 
Table 1. Clinical, biological and histological features of patients.

\begin{tabular}{|c|c|c|c|}
\hline & Normal & AIH Untreated & AIH Treated \\
\hline Number of individuals & 10 & 11 & 5 \\
\hline Sex, male/female & $6 / 4$ & $5 / 6$ & $2 / 3$ \\
\hline Age, y (mean \pm SD) & $47.3 \pm 4.8$ & $48.5 \pm 7.3$ & $51.6 \pm 6.8$ \\
\hline ALT, U/L (median; range) & $33 ; 17-79$ & $327 ; 44-2279$ & $47 ; 25-836$ \\
\hline AST, U/L (median; range) & $29 ; 20-71$ & $337 ; 31-982$ & $55 ; 21-1212$ \\
\hline IgG, g/L (median; range) & - & $15.4 ; 12.3-22.2$ & $12.8 ; 10.9-34.2$ \\
\hline IgA, g/L (median; range) & - & $3.1 ; 1.6-4.5$ & $3.0 ; 2.8-4.6$ \\
\hline $\begin{array}{l}\mathrm{SMA}^{+} \text {titer }(>1: 80), \text { Yes } / \text { No } \\
\text { (median; range) }\end{array}$ & - & $\begin{array}{c}9 / 3 \\
(160 ;<40-1280)\end{array}$ & $\begin{array}{c}2 / 3 \\
(80 ;<40-640)\end{array}$ \\
\hline $\begin{array}{l}\mathrm{ANA}^{+} \text {titer }(>1: 80), \text { Yes/No } \\
\text { (median; range) }\end{array}$ & - & $\begin{array}{c}10 / 1 \\
(320 ;<80-1280)\end{array}$ & $\begin{array}{c}4 / 1 \\
(160 ;<40-320)\end{array}$ \\
\hline $\begin{array}{c}\text { Treatment } \\
\text { None } \\
\text { Steroids/Steroids + Azathioprine }\end{array}$ & $\begin{array}{l}10 \\
-\end{array}$ & $\begin{array}{c}11 \\
-\end{array}$ & $\begin{array}{c}- \\
2 / 3\end{array}$ \\
\hline $\begin{array}{l}\text { Histology, METAVIR scoring } \\
\text { Fibrosis stage (F0/F1-F2/F3-F4) } \\
\text { Activity score (A0/A1/A2/A3) }\end{array}$ & $\begin{array}{c}9 / 1 / 0 \\
-\end{array}$ & $\begin{array}{c}1 / 8 / 2 \\
2 / 3 / 1 / 5\end{array}$ & $\begin{array}{c}1 / 1 / 3 \\
2 / 2 / 1 / 0\end{array}$ \\
\hline
\end{tabular}

Alanine transaminase, ALT; Aspartate transaminase, AST; Smooth muscle antibody, SMA; Antinuclear antibody, ANA.

\subsection{Flow Cytometry Analyses}

Immediately after the needle liver biopsy, freshly harvested liver tissue was transferred in the Hypothermosol ${ }^{\mathrm{TM}} \mathrm{FRS}$ solution $\left(4^{\circ} \mathrm{C}\right)$, the weight of the tissue was determined and cells were recovered through mechanical disruption as previously $[16,17]$. Intrahepatic cell suspension was immunostained (without any stimulation), with the following antihuman antibodies of surface markers: Tube 1 included anti-CD45-APC/Cy7 (clone HI30, BioLegend, San Diego, CA, USA), anti-CD3-PerCP-Cy5.5 (clone UCHT1, BioLegend), antiCD56-BV605 (clone HCD56, BioLegend), anti-CD16-AF700 (clone 3G8, BioLegend), antiCD15-BV510 (clone W6D3, BioLegend), anti-CD8-PE/Cy7 (clone RPA-T8, BD Biosciences, Le Pont-De-Claix, France), anti-CD69-PE (clone FN50, BioLegend), anti-PD-L1-FITC (clone MIH1, BD Bioscience), anti-CTLA4-BV421 (clone BNI3, BioLegend) and anti-PD-1-BV711 (clone EH12.2H7, BioLegend). Tube 2 included anti-CD45-APC/Cy7 (clone HI30, BioLegend), anti-CD3-PerCP-Cy5.5 (clone UCHT1, BioLegend), anti-CD56-BV605 (clone HCD56, BioLegend), anti-CD16-AF700 (clone 3G8, BioLegend), anti-CD15-BV510 (clone W6D3, BioLegend), anti-CD8-PE/Cy7 (clone RPA-T8, BD Biosciences), anti-LAG3-PE (clone 3DS223H, eBioscience), anti-OX40-FITC (clone Ber-ACT35, BioLegend), anti-4-1BBBV421 (clone 4B4-1, BioLegend) and anti-TIM3-BV785 (clone F39-2E2, BioLegend). The fluorescence minus one (FMO) controls, same as the corresponding isotype controls were used to determine positive populations. Zombie UV ${ }^{\mathrm{TM}}$ Fixable Viability kit was used to exclude dead cells. FluoroFix ${ }^{\mathrm{TM}}$ Buffer (Biolegend) was used for fixation to stabilize tandem dyes. Data were acquired on BD-LSRII flow cytometer (BD Biosciences), collected with BD FACSDiva 6.3.1 software and analyzed using FCS Express 6 Flow software.

\subsection{Statistical Analysis}

Analyses were performed using the statistical software GraphPad Prism 6 (GraphPad Software, San DiegoCity, CA, USA). Normal distribution was tested by means of the D'Agostino-Pearson omnibus normality test. When data were normally distributed, the unpaired $t$-test was used to determine significant differences observed between the groups. On the other hand, when data from either cohort were not normally distributed, the Mann-Whitney test was performed. The non-parametric Kruskal-Wallis one-way analysis of variance was used for multiple comparisons. $p$ value $<0.05$ was considered to be significant. Spearman correlation non-parametric test was conducted to determine the 
degree of correlation between variables when at least one variable's data was non-normally distributed. $p$-values in correlation matrix were adjusted by Bonferroni correction method.

\section{Results}

\subsection{The Number and Distribution of Intrahepatic Lymphocytes Are Modified in AIH}

In this study, we analyzed 26 liver biopsies divided into following groups: (i) AIH untreated $(n=11)$, (ii) AIH treated $(n=5)$ and (iii) Normal $(n=10)$. The exact weight of the biopsy was determined (mean $=6.2 \pm 0.14 \mathrm{mg}$ of tissue) to begin with, followed by tissue homogenization. Fresh samples were stained using two different panels for the identification of the major lymphocyte populations and the expression of immune checkpoint molecules by flow cytometry.

We investigated T, NK, NKT, and B cells adopting the strategy with the principle of gating as previously described $[16,18,19]$. The estimated number of cells per mg of tissue was calculated based on the original weight of the biopsy. As expected, the number of $\mathrm{CD}^{+} 5^{+}$lymphocytes per $1 \mathrm{mg}$ was significantly higher in AIH untreated group (5025 \pm 740 , $p=0.0012)$ compared to Normal (1954 \pm 241$)$, which was mainly caused by a significant accumulation of T cells in AIH untreated group (2933 \pm 494 of T cells per $1 \mathrm{mg}, p=0.0016)$ compared to Normal (924 \pm 174$)$, Figure 1a. Similarly, we observed an abnormal intrahepatic accumulation of B cells in the AIH untreated group ( $211 \pm 52$ of B cells per $1 \mathrm{mg}$, $p=0.0159)$ compared to Normal group $(65 \pm 9)$, Figure 1a. The intrahepatic accumulation of lymphocytes was normalized in the AIH treated group, showing $2369 \pm 561 \mathrm{CD}^{+} 5^{+}$ lymphocytes per $1 \mathrm{mg}$ of liver, $900 \pm 175 \mathrm{~T}$ cells per $1 \mathrm{mg}$ of liver and $50 \pm 15 \mathrm{~B}$ cells per $1 \mathrm{mg}$ of liver. Concerning the estimated number of NK and NKT cells per $\mathrm{mg}$ of tissue, we observed no statistically significant differences between the groups.

a)

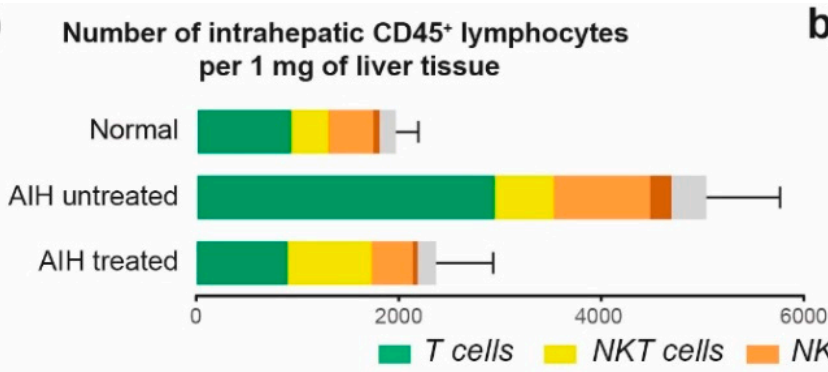

c)

Number of intrahepatic T cells per $1 \mathrm{mg}$ of liver tissue

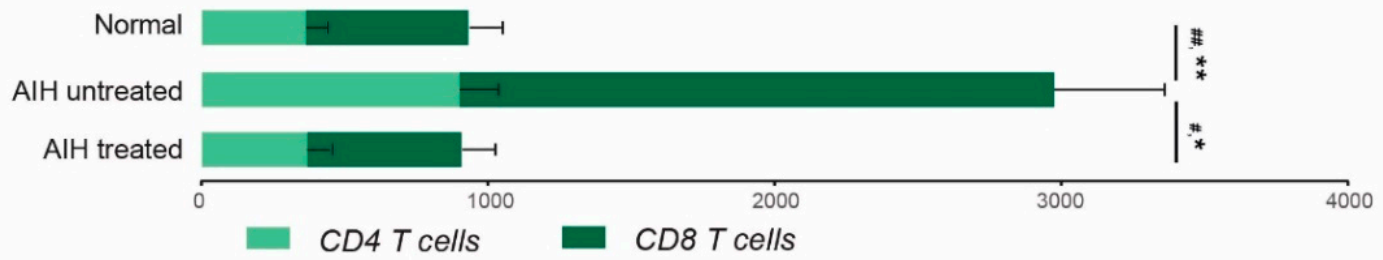

b)

Distribution of intrahepatic immune cells in CD45+ lymphocyte population

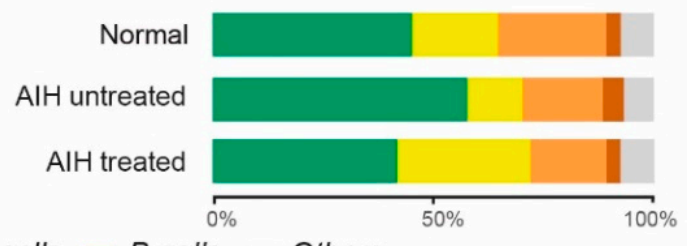

d)

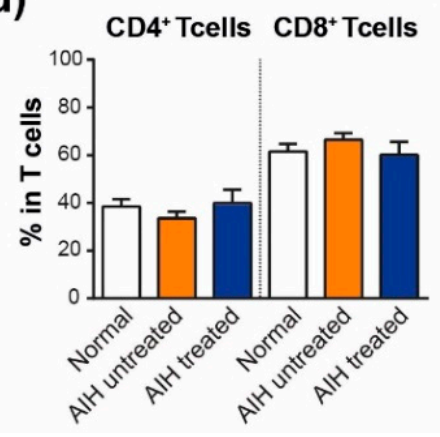

e)

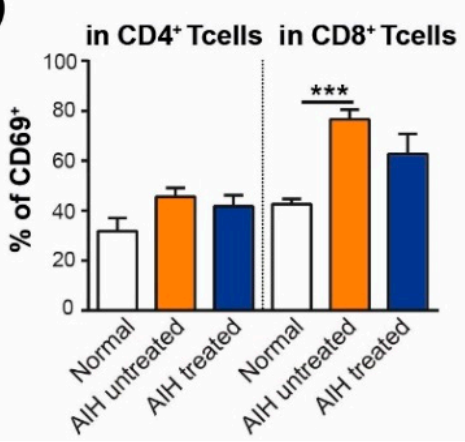

f)

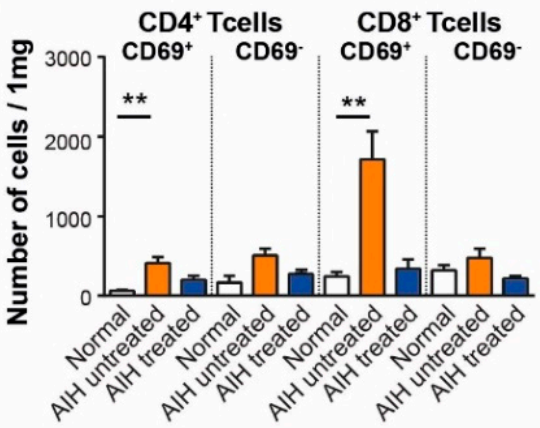

Figure 1. Number and distribution of intrahepatic lymphocytes is modified in AIH. (a) Estimated number of CD45 $5^{+}$lymphocytes 
per $1 \mathrm{mg}$ of liver tissue. (b) Frequency of intrahepatic immune cells in CD45 lymphocytes. (c) Estimated number of intrahepatic T cells per $1 \mathrm{mg}$ of liver tissue. \# $p<0.05$, \#\# $p<0.01$ represent statistically significant difference in number of $\mathrm{CD}^{+} \mathrm{T}$ cells between groups, ${ }^{*} p<0.05,{ }^{* *} p<0.01$ represent statistically significant difference in number of CD8 ${ }^{+} \mathrm{T}$ cells between groups. Kruskal-Wallis test with Dunn multiple comparison post-test. (d) Frequency of intrahepatic $\mathrm{CD}^{+} \mathrm{T}$ cells and $\mathrm{CD}^{+} \mathrm{T}$ cells in $\mathrm{T}$ cell population. (e) Frequency of intrahepatic CD69 ${ }^{+}$cells in $\mathrm{CD} 4^{+} \mathrm{T}$ cell and in $\mathrm{CD} 8^{+} \mathrm{T}$ cell population. (f) Estimated number of $\mathrm{CD} 69^{+}$or $\mathrm{CD} 69^{-} \mathrm{CD} 4^{+} \mathrm{T}$ cells and $\mathrm{CD} 69^{+}$or $\mathrm{CD} 69^{-} \mathrm{CD} 8^{+} \mathrm{T}$ cells per $1 \mathrm{mg}$ of liver tissue. ${ }^{*} p<0.05,{ }^{* *} p<0.01,{ }^{* * *} p<0.001$ between groups, Kruskal-Wallis test with Dunn multiple comparison post-test. Data are expressed as mean \pm SEM. Normal $(n=10)$, AIH untreated $(n=11)$ and AIH treated $(n=5)$.

The overall distribution of intrahepatic immune cells in $\mathrm{CD} 45^{+}$lymphocyte population differed between groups in this study. $\mathrm{CD}^{+} \mathrm{CD}^{-} 6^{-} \mathrm{T}$ cells found in the AIH untreated biopsies accounted for more than $57.7 \pm 3.6 \%$ of all CD $45^{+}$lymphocytes, whereas in Normal group, T cells represented only $45.2 \pm 4.4 \%(p=0.0390)$. On the other hand, CD3 ${ }^{+} \mathrm{CD}^{+} 6^{+}$ $\mathrm{NKT}$ cells and $\mathrm{CD}^{-} \mathrm{CD}^{-} 6^{+} \mathrm{NK}$ cells represented a non-significantly smaller population in AIH untreated group (12.5 and 18.2\%) compared to Normal liver (19.5 and 24.4\%), Figure $1 b$, even though their absolute numbers per tissue were similar (Figure 1a). The analysis of tissue from AIH patients during treatment revealed that both the number and distribution of intrahepatic immune cells were normalized (Figure 1a,b).

\subsection{Activated $C D 8^{+} T$ Cells Are Accumulated in the Liver of Patients with AIH}

The estimated number of $\mathrm{CD}^{+} \mathrm{T}$ cells per $1 \mathrm{mg}$ of tissue was significantly increased in AIH untreated group compared to Normal group (893 \pm 133 vs. $365 \pm 76$ of CD4 ${ }^{+}$T cells per $1 \mathrm{mg}, p=0.0033$, Figure 1c). Similarly, we observed a dramatic accumulation of $\mathrm{CD}^{+} \mathrm{T}$ cells per $1 \mathrm{mg}$ of tissue in AIH untreated group compared to Normal group (2040 $\pm 382 \mathrm{vs}$. $559 \pm 101$ of $\mathrm{CD}^{+} \mathrm{T}$ cells per $1 \mathrm{mg}, p=0.0020$, Figure $1 \mathrm{c}$ ).

Importantly, the number of intrahepatic $\mathrm{CD} 4^{+} \mathrm{T}$ cells and $\mathrm{CD} 8^{+} \mathrm{T}$ cells was normalized in AIH patients during treatment, with significant decrease in number of cells when compared to AIH untreated group, Figure 1c. The ratio of intrahepatic CD4 ${ }^{+} \mathrm{T}$ cells to $\mathrm{CD}^{+} \mathrm{T}$ cells was similar in all groups, with $\mathrm{CD}^{+} \mathrm{T}$ cells representing approximately $65 \%$ of the $\mathrm{T}$ cell population (Figure $1 \mathrm{~d}$ ).

The massive increase of number of $\mathrm{CD}^{+} \mathrm{T}$ cells (Figure 1c) was associated with significantly higher frequency of $\mathrm{CD}^{+} \mathrm{T}$ expressing activation marker CD69 in the AIH untreated group compared to Normal group (76.6 \pm 3.9 vs. $42.6 \pm 2.1 \%$ of $\mathrm{CD}^{+} 9^{+}$cells per $\mathrm{CD}^{+} \mathrm{T}$ cells, $p=0.0020$, Figure $\left.1 \mathrm{e}\right)$. Based on the estimated number of cells, untreated AIH is characterized by the accumulation of both, activated $\mathrm{CD} 69^{+} \mathrm{CD} 4^{+}$and $\mathrm{CD} 69^{+} \mathrm{CD} 8^{+} \mathrm{T}$ cells in the liver, while the population of $\mathrm{CD}^{-} 9^{-} \mathrm{T}$ cells does not statistically differ between groups (Figure 1f).

\subsection{High Frequency of PD-1 $1^{+}$and $4-1 B B^{+} T$ Cells in the Liver of Patients with AIH}

Next, we analyzed the distribution of immune checkpoint molecules on the cell surface of $\mathrm{CD}^{+}$and CD8 ${ }^{+}$T cells, including inhibitory PD-1, TIM3, LAG3, CTLA4 and stimulatory 4-1BB and OX40 molecules (Figure 2).

The frequency of $\mathrm{CD}^{+} \mathrm{T}$ cells expressing stimulatory checkpoint molecule 4-1BB and OX40 was significantly higher in AIH untreated group compared to Normal group $\left(4-1 \mathrm{BB}^{+} \mathrm{CD}^{+} \mathrm{T}\right.$ cells: $5.2 \pm 0.7 \%$ vs. $1.4 \pm 0.6 \%, p=0.0010, \mathrm{OX} 40^{+} \mathrm{CD}^{+} \mathrm{T}$ cells: $6.6 \pm 0.9 \%$ vs. $3.4 \pm 1.4 \%, p=0.0443$ ), while the inhibitory immune checkpoint molecules were similarly expressed by $\mathrm{CD}^{+} \mathrm{T}$ cells from different groups. Intrahepatic $\mathrm{CD} 8^{+} \mathrm{T}$ cells were characterized by a significantly higher frequency of cells expressing PD-1 in AIH untreated group, compared to Normal $(57.4 \pm 4.2 \%$ vs. $17.0 \pm 3.1 \%, p<0.0001)$, the same as a higher frequency of $\mathrm{CD}^{+} \mathrm{T}$ cells expressing $4-1 \mathrm{BB}^{+}(8.1 \pm 2.0 \%$ vs. $1.5 \pm 0.4 \%, p=0.0011$, Figure 2a,b). Importantly, PD-1 was almost exclusively co-expressed with CD69 activation marker on $\mathrm{CD}^{+} \mathrm{T}$ cells in $\mathrm{AIH}$ patients (Figure 2c). 
a)
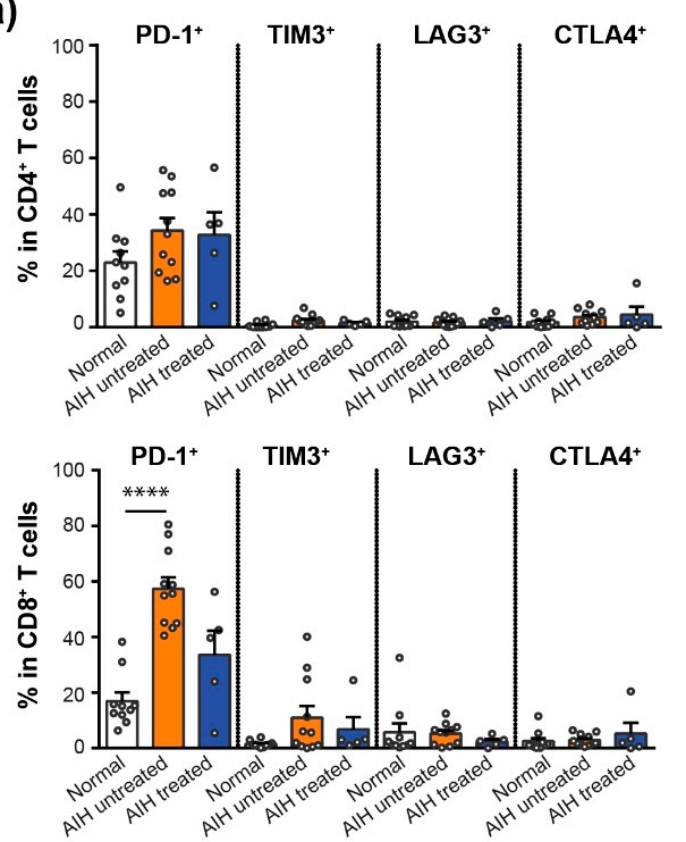

d)

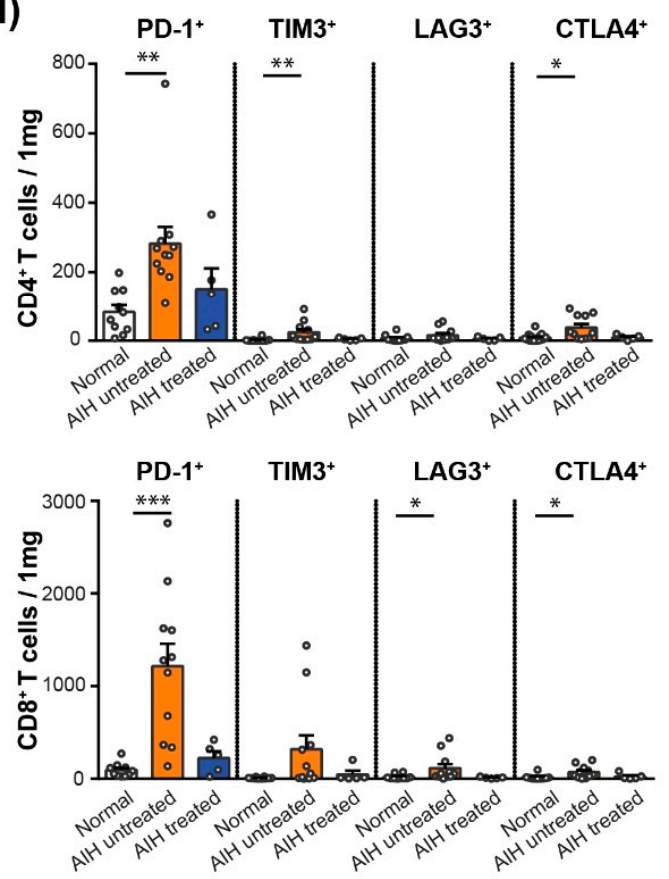

b)
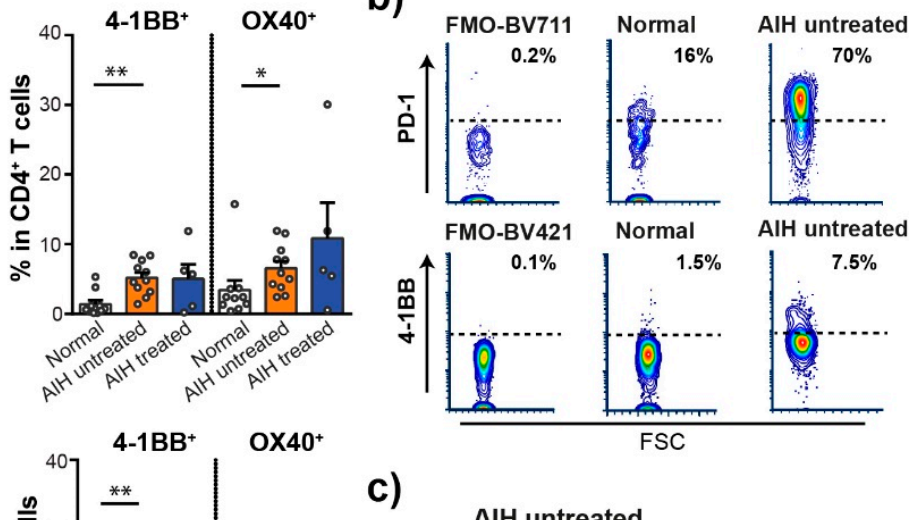

c)

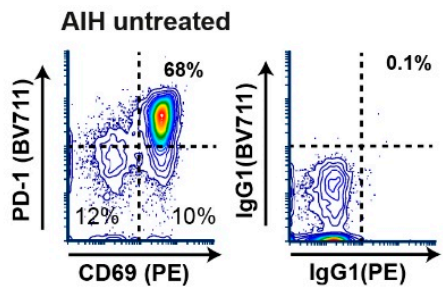

e)
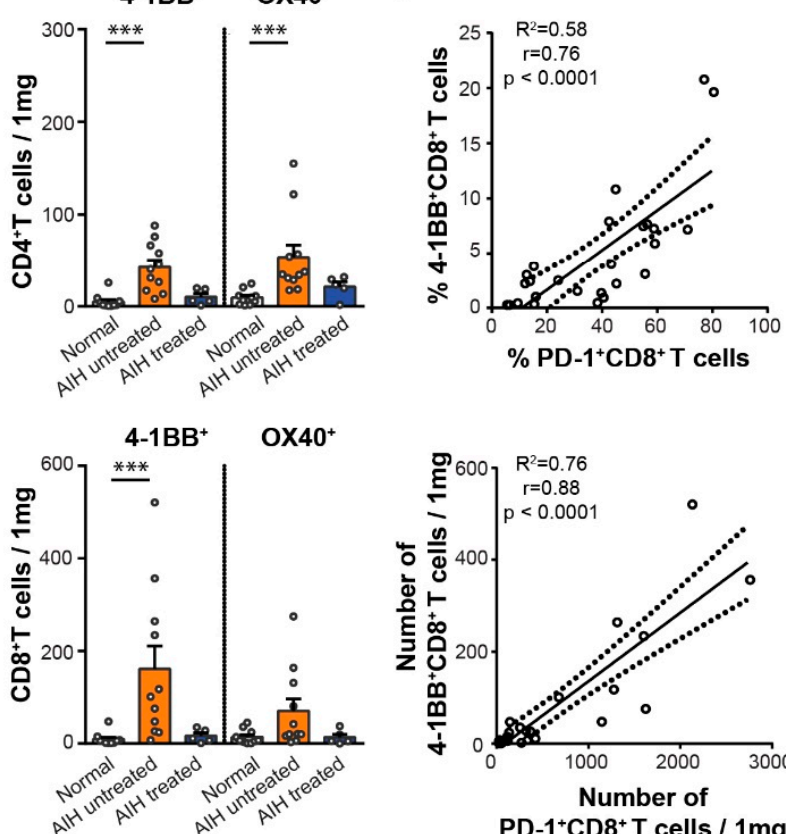

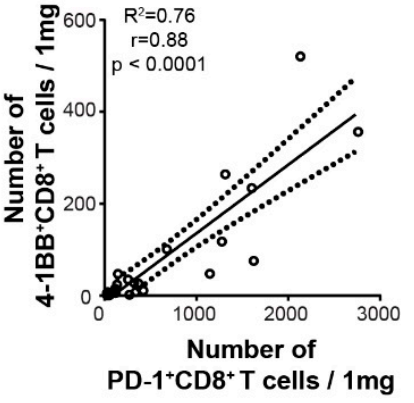

Figure 2. Immune checkpoint molecule expression on intra-hepatic CD8 and CD4 T cells in different subgroups. (a) The frequency of intrahepatic immune checkpoint molecule positive CD4 ${ }^{+}$and CD8 ${ }^{+}$T cells. Normal $(n=10)$, AIH untreated $(n=11)$ and AIH treated $(n=5)$. Each circle represents a patient. Data are expressed as mean \pm SEM, ${ }^{*} p<0.05,{ }^{* *} p<0.01$, ${ }_{* * * *} p<0.0001$ between groups (Kruskal-Wallis test with Dunn multiple comparison post-test). (b) Representative flow cytometry contour plot showing the expression of intrahepatic PD-1 on CD8 ${ }^{+} \mathrm{T}$ cells and 4-1BB on CD4 ${ }^{+} \mathrm{T}$ cells in fluorescence minus one control sample (FMO), in normal liver biopsy and in biopsy from patient with untreated AIH. (c) Representative flow cytometry contour plot showing the co-expression of PD-1 and CD69 in intrahepatic CD8 ${ }^{+} \mathrm{T}_{\text {cells }}$ of patient with untreated AIH. (d) An estimated number of intrahepatic immune checkpoint positive CD4 ${ }^{+} \mathrm{T}_{\text {cells and CD8 }}^{+}$ T cells per $1 \mathrm{mg}$ of liver tissue. Normal $(n=10)$, AIH untreated $(n=11)$ and AIH treated $(n=5)$. Each circle represents a patient. Data are expressed as mean $\pm \mathrm{SEM},{ }^{*} p<0.05,{ }^{* * *} p<0.001$ between groups (Kruskal-Wallis test with Dunn multiple comparison post-test). (e) The correlation between the frequency of $4-1 \mathrm{BB}^{+}$and $\mathrm{PD}-\mathrm{1}^{+} \mathrm{CD} 8^{+} \mathrm{T}$ cells (upper graph) and the correlation between the number of $4-\mathrm{BB}^{+}$and $\mathrm{PD}-\mathrm{1}^{+} \mathrm{CD} 8^{+} \mathrm{T}$ cells (lower graph). ( $\mathrm{R}^{2}$ ) R-squared, (r) Spearman correlation coefficient. Each circle represents a patient. 
The analysis, focused on estimated numbers of T cells expressing ICM per $1 \mathrm{mg}$ of tissue, revealed that PD-1, TIM3, CTLA4, 4-1BB and OX40 positive CD4 ${ }^{+}$T cells are highly accumulated in AIH untreated liver compared to normal liver tissue. Similarly, we observed higher numbers of PD-1, LAG3, CTLA4 and 4-1BB positive CD8 ${ }^{+} \mathrm{T}$ cells in untreated AIH patients compared to Normal group (Figure 2d). Since we analyzed the markers of immune checkpoint receptors in two separated tubes, we cannot provide data pertaining to their co-expression per individual cell. However, we specifically investigated the co-expression of 4-1BB with other markers in $4 \mathrm{AIH}$ patients, and our data revealed that 4-1BB is expressed on cells positive for PD-1 and CD69 (Supplementary Figure S1a). Moreover, the positive correlation between both the frequency and the number of $\mathrm{CD} 8^{+} \mathrm{T}$ cells expressing 4-1BB or PD-1 supports the co-expression of those receptors, as shown in Figure 2e.

Analyses targeting intrahepatic NK, NKT and B cells did not show any significant differences in ICM expression between groups. In addition, the distribution of intrahepatic NK cells into subpopulations of $\mathrm{CD}_{16}^{-}$and $\mathrm{CD} 16^{+}$was similar between all groups (Supplementary Figure S1b-d).

\subsection{Intrahepatic T Cells Correlate Positively with Markers of Liver Pathology}

Next, we investigated the possible association between clinical data and lymphocyte characteristics in the group of untreated AIH patients. First, correlation analysis revealed a positive association of ALT and AST levels with the number of intrahepatic T cells (Figure 3).

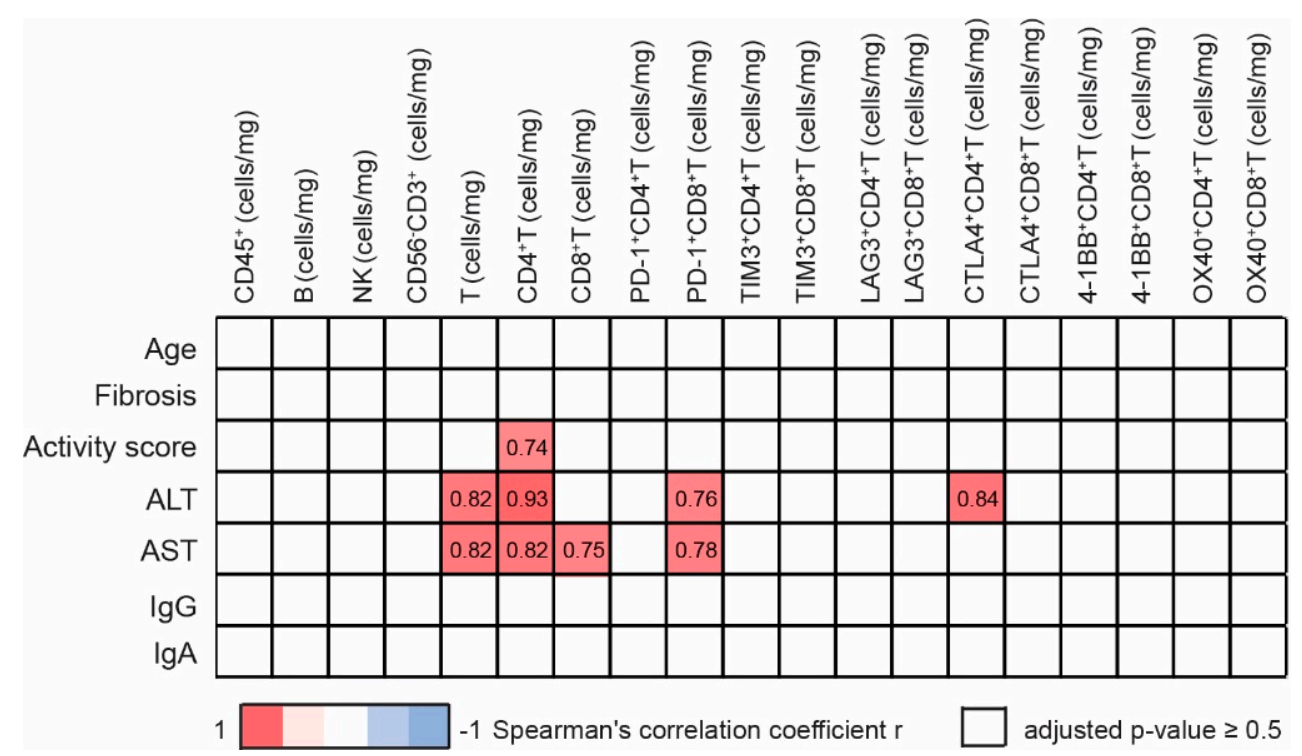

Figure 3. Correlation of patient characteristics and intrahepatic lymphocyte characteristics in untreated AIH group. Only significant correlations (Bonferroni-corrected $p$ value $<0.5$ ) are reported, numbers correspond to Spearman correlation coefficient $r$, positive correlation (red), negative correlation (blue), $n=11$.

A positive association of activity score, ALT and AST levels was also observed with the number of intrahepatic $\mathrm{CD}^{+} \mathrm{T}$ cells. Similarly, AST levels positively correlated with intrahepatic $\mathrm{CD} 8^{+} \mathrm{T}$ cells, Figure 3. Strong positive correlation was also observed between the number of intrahepatic PD- $1^{+} \mathrm{CD} 8^{+} \mathrm{T}$ cells and ALT and AST levels. The number of intrahepatic CTLA $-4^{+} \mathrm{CD} 4^{+} \mathrm{T}$ cells correlated positively with ALT levels.

Surprisingly, correlation analysis revealed no association of activity score or AST and ALT levels with number of intrahepatic PD- $1^{+} \mathrm{CD} 4^{+} \mathrm{T}$ cells, suggesting the different role of intrahepatic PD- $1^{+} \mathrm{CD} 4^{+} \mathrm{T}$ cells and PD- $1^{+} \mathrm{CD} 8^{+} \mathrm{T}$ cells in the immune-pathogenesis of AIH. Similarly, no association was observed between clinical data and number of $4-1 \mathrm{BB}^{+} \mathrm{T}$ cells in the group of untreated AIH patients. 
The importance of intrahepatic PD- $1^{+} \mathrm{CD} 8^{+} \mathrm{T}$ cells was confirmed when the association between clinical data and lymphocyte characteristics was analyzed in whole cohort (Supplementary Figure S1e).

\section{Discussion}

In the present study, we performed multiparametric flow cytometry analysis based on fresh liver biopsy samples from patients with AIH. We analyzed a large panel of intrahepatic ICM (PD-1, TIM3, LAG3, CTLA-4, OX40, 4-1BB) expressed by different immune cells, and demonstrated that untreated $\mathrm{AIH}$ patients are characterized by a high frequency of activated intrahepatic T cells expressing PD-1 and 4-1BB, Figure 4. The analysis of tissue from AIH patients during treatment revealed that both the number and distribution of intrahepatic immune cells are normalized during treatment while the expression of ICM seems to be normalized only partially.

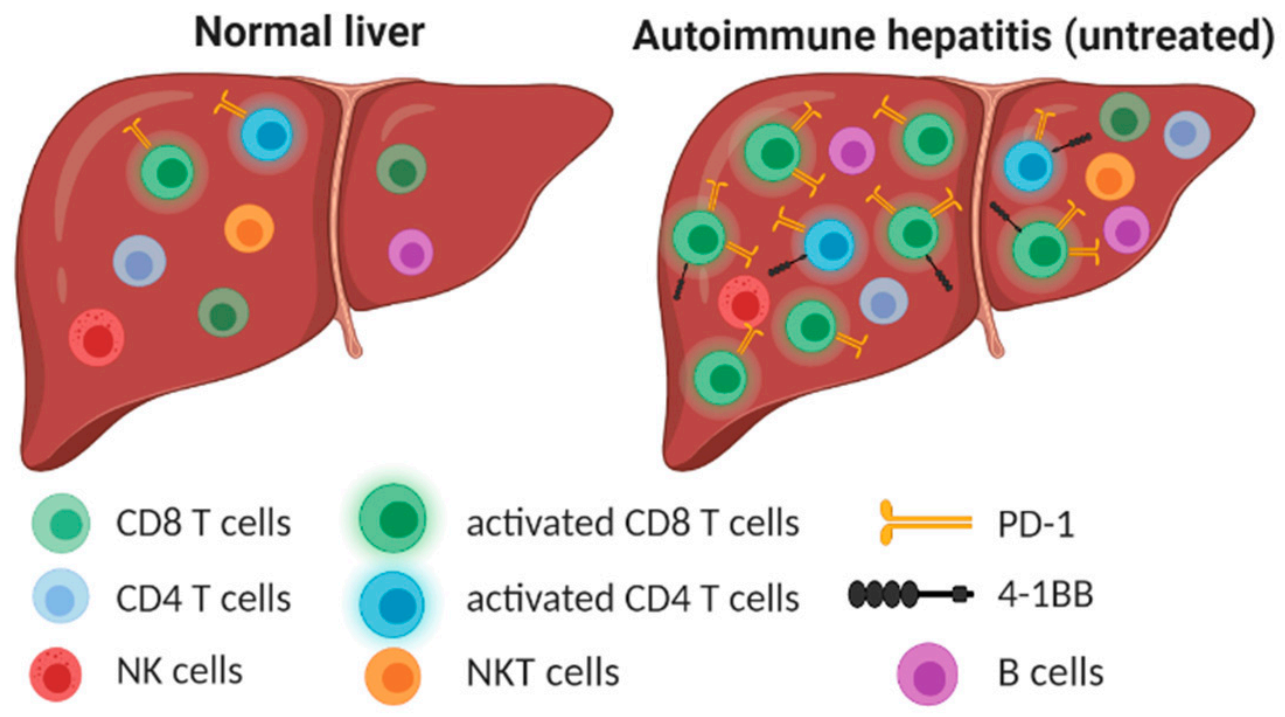

Figure 4. Untreated $\mathrm{AIH}$ is characterized by high accumulation of activated $\mathrm{T}$ cells with increased expression of PD-1 and 4-1BB immune checkpoint molecules. Created with BioRender.com.

Importantly, the accumulation of $\mathrm{PD}-1^{+} \mathrm{CD}^{+} \mathrm{T}$ cells in the untreated AIH patientderived liver tissue correlated positively with liver pathology (ALT and AST levels). The possible involvement of PD-1/PD-L1 pathway in the pathogenesis of AIH was previously described in mice model of experimental AIH [20] and in human studies [21,22]. Our results are in accordance with Oikawa et al., who previously demonstrated by immunohistochemistry that PD-1 ICM is expressed on more than half of the intrahepatic T cells in patients with AILD [21]. Similarly, a recent study showed a high frequency of PD-1 positive cells within liver tissue in children with AIH [22]. However, neither of these studies determined the exact type of intrahepatic T cells that express the PD-1 molecule. Circulating levels of PD-1 are also increased in AILD, as recent studies have shown that circulating levels of soluble PD-1 are elevated in AIH patients [23,24]. In addition, it was demonstrated that PD-1 and CD38 co-expression by circulating memory CD45RA ${ }^{-} \mathrm{CXCR}^{-} \mathrm{CD}^{-} 7^{-}$ $\mathrm{CD} 27^{+} \mathrm{T}$ cells reflects AIH activity [25].

Compared to previous studies, we analyzed intrahepatic lymphocytes by multiparametric flow cytometry, which allowed us to differentiate individual sub-populations of immune cells expressing PD- 1 in liver. Here, we reveal the importance of CD8 ${ }^{+} \mathrm{T}$ cells and the positive correlation between the intrahepatic accumulation of PD- $1^{+} \mathrm{CD} 8^{+} \mathrm{T}$ cells and AIH severity. On the other hand, we observed that the number of PD- $1^{+} \mathrm{CD} 4^{+} \mathrm{T}$ cells was not associated with AIH severity, suggesting the different role of intrahepatic PD- $1^{+} \mathrm{CD} 4^{+}$ T cells and PD- $1^{+}$CD8 ${ }^{+}$T cells in the immune-pathogenesis of AIH. Indeed, it was reported that PD-1 signaling promotes immunosuppressive functions of $\mathrm{CD}^{+} \mathrm{T}$ cells, mainly of 
regulatory Foxp $3^{+} \mathrm{CD} 4^{+} \mathrm{T}$ cells [26]. Small liver biopsy size did not allow us to analyze the intracellular expression of Foxp3 ${ }^{+}$, which is a limitation of this study. Indeed, Foxp3 ${ }^{+} \mathrm{CD}^{+}$ $\mathrm{T}$ cells are known to be enriched in the liver of untreated AIH patients $[27,28]$ and decrease during therapy [28], showing an important role of this subpopulation of $\mathrm{CD} 4^{+} \mathrm{T}$ cells in liver. In future, it will be important to reveal the role of intrahepatic PD $-1^{+} \mathrm{CD} 4^{+}$Treg cells, their features, same as their proliferation and apoptosis status in autoimmune liver injury.

A growing body of evidence highlights the key role of the $\mathrm{T}$ cell costimulatory receptor 4-1BB for immune homeostasis. 4-1BB-deficient mice have impaired T-cell survival, proliferation and cytotoxicity [29]. 4-1BB-mediated $\mathrm{T}$ cell stimulation as measured by enhanced $\mathrm{T}$ cell proliferation and cytokine production can be induced by anti-4-1BB monoclonal antibodies or by employing the 4-1BB ligand. Today, agonist antibodies targeting 4-1BB are among the most effective immunotherapeutic agents across preclinical cancer models. However, early clinical studies have revealed that 4-1BB agonists can trigger high-grade liver inflammation. Thus, the development of these agents has been hampered due to the risk of severe liver toxicity [30]. Despite the strong capacity of 4-1BB activation to trigger hepatotoxicity, only a few studies have focused on the possible role of 4-1BB in AILD. A previous study showed a high level of intrahepatic 4-1BB in a mouse model of concanavalin (Con) A-induced immune-mediated liver injury. Importantly, blocking anti-4-1BB monoclonal antibodies attenuated the liver pathology in this animal model [31]. Bartkowiak et al. demonstrated recently that $4-1 \mathrm{BB}$ agonist antibodies trigger hepatitis via activation of 4-1BB on liver myeloid cells, which leads to CD8 T cells infiltration, tissue damage and transaminase elevation [32]. Thus, the expression of 4-1BB on liver myeloid cells in AILD deserves to be further investigated. Altogether, these results suggest that the inhibition of the 4-1BB pathway might be the next step toward new therapeutic approaches to control AIH. Paradoxically, the stimulation of 4-1BB with agonist antibodies also inhibits inflammation in many murine models of autoimmunity, which may be due to augmentation of regulatory CD8 T cell activity and/or driving the death of pathogenic CD4 T cells. Our study revealed that the frequency of intrahepatic 4-1BB positive $T$ cells expression is high in AIH without any correlation with severity of AIH. Further investigation based on a larger number of patients is necessary to investigate possible association between clinical data and 4-1BB.

There are only a few studies addressing the involvement of other ICM in the pathology of AIH. For instance, the possible link of defective TIM3 pathway in AIH was identified previously on circulating lymphocytes [33]. Here, we have shown the significant accumulation of intrahepatic T cells expressing not only PD-1 and 4-1BB, but also TIM3, LAG3, CTLA4 and OX40 in AIH when compared to normal liver, and a possible association between their expression and liver pathology.

In summary, analysis of AIH patient-derived liver tissue revealed the expression of ICM and the link with liver pathology, as well as the strong correlation between PD- $1^{+} \mathrm{CD} 8^{+} \mathrm{T}$-cell abundance and AIH severity. Recently, Zhao et al. showed that the depletion of PD-1 ${ }^{+}$cells may ameliorate autoimmune disease in different mouse models [34], but the manageable selectivity of treatment for $\mathrm{CD} 8^{+}$vs. $\mathrm{CD} 4^{+} \mathrm{T}$ cells should be carefully investigated.

Our results clearly show that the ICM are highly expressed in AIH and play an important role in the loss of immune homeostasis in the liver, providing an attractive approach to investigate their potential role as targets for effective therapeutic interventions.

Supplementary Materials: The following are available online at https:/ / www.mdpi.com/article/10.3 390/cells10102671/s1, Figure S1. Immune checkpoint molecule expression on intra-hepatic NK and NKT cells and the correlation of patient characteristics and intra-hepatic lymphocyte characteristics.

Author Contributions: Conceptualization, Z.M.J., J.-P.Z. and T.D.; methodology, Z.M.J.; software, Z.M.J.; validation, Z.M.J., M.N.H. and T.D.; formal analysis, Z.M.J., M.M.-R. and N.S.; investigation, Z.M.J., M.N.H., T.G., N.S. and C.C.; resources, Z.M.J., M.N.H., V.L., T.G. and C.C.; writing-original draft preparation, Z.M.J.; writing—review and editing, Z.M.J., J.-P.Z., P.N.M., C.C. and T.D.; visualization, Z.M.J.; supervision, Z.M.J. and T.D.; project administration, V.L. and T.D.; funding acquisition, J.-P.Z., V.L. and T.D. All authors have read and agreed to the published version of the manuscript. 
Funding: This research was funded by "Fonds Agir pour les Maladies Chroniques", France.

Institutional Review Board Statement: The study was conducted according to the guidelines of the Declaration of Helsinki, and approved by the Ethics Committee of CHU Grenoble-Alpes: the patient collection number AC-2019-3627 (CRB03). The biological resource center of CHU Grenoble-Alpes (nBRIF BB-0033-00069).

Informed Consent Statement: Informed consent was obtained from all subjects involved in the study.

Data Availability Statement: The data presented in this study are available on request from the corresponding author. The data are not publicly available due to restrictions in informed consent.

Conflicts of Interest: The authors declare no conflict of interest.

\section{References}

1. Carbone, M.; Neuberger, J.M. Autoimmune liver disease, autoimmunity and liver transplantation. J. Hepatol. 2014, 60, 210-223. [CrossRef]

2. Valgeirsson, K.B.; Hreinsson, J.P.; Björnsson, E.S. Increased incidence of autoimmune hepatitis is associated with wider use of biological drugs. Liver Int. 2019, 39, 2341-2349. [CrossRef] [PubMed]

3. Takahashi, A.; Ohira, H.; Abe, K.; Zeniya, M.; Abe, M.; Arinaga-Hino, T.; Torimura, T.; Yoshizawa, K.; Takaki, A.; Kang, J.-H.; et al. Increasing incidence of acute autoimmune hepatitis: A nationwide survey in Japan. Sci. Rep. 2020, 10, 14250. [CrossRef] [PubMed]

4. Grønbæk, L.; Otete, H.; Ban, L.; Crooks, C.; Card, T.; Jepsen, P.; West, J. Incidence, prevalence and mortality of autoimmune hepatitis in England 1997-2015. A population-based cohort study. Liver Int. 2020, 40, 1634-1644. [CrossRef] [PubMed]

5. Mieli-Vergani, G.; Vergani, D.; Czaja, A.J.; Manns, M.P.; Krawitt, E.L.; Vierling, J.M.; Lohse, A.W.; Montano-Loza, A.J. Autoimmune hepatitis. Nat. Reviews. Dis. Primers 2018, 4, 18017. [CrossRef]

6. Marschall, H.U.; Henriksson, I.; Lindberg, S.; Söderdahl, F.; Thuresson, M.; Wahlin, S.; Ludvigsson, J.F. Incidence, prevalence, and outcome of primary biliary cholangitis in a nationwide Swedish population-based cohort. Sci. Rep. 2019, 9, 11525. [CrossRef]

7. Jepsen, P.; Grønbæk, L.; Vilstrup, H. Worldwide Incidence of Autoimmune Liver Disease. Dig. Dis. 2015, 33 (Suppl. 2), 2-12. [CrossRef]

8. Blachier, M.; Leleu, H.; Peck-Radosavljevic, M.; Valla, D.C.; Roudot-Thoraval, F. The burden of liver disease in Europe: A review of available epidemiological data. J. Hepatol. 2013, 58, 593-608. [CrossRef]

9. Bovensiepen, C.S.; Schakat, M.; Sebode, M.; Zenouzi, R.; Hartl, J.; Peiseler, M.; Li, J.; Henze, L.; Woestemeier, A.; Schramm, C.; et al. TNF-Producing Th1 Cells Are Selectively Expanded in Liver Infiltrates of Patients with Autoimmune Hepatitis. J. Immunol. 2019, 203, 3148-3156. [CrossRef]

10. Than, N.N.; Jeffery, H.C.; Oo, Y.H. Autoimmune Hepatitis: Progress from Global Immunosuppression to Personalised Regulatory T Cell Therapy. Can. J. Gastroenterol. Hepatol. 2016, 2016, 7181685. [CrossRef]

11. Lohse, A.W.; Sebode, M.; Jørgensen, M.H.; Ytting, H.; Karlsen, T.H.; Kelly, D.; Manns, M.P.; Vesterhus, M. Second-line and third-line therapy for autoimmune hepatitis: A position statement from the European Reference Network on Hepatological Diseases and the International Autoimmune Hepatitis Group. J. Hepatol. 2020, 73, 1496-1506. [CrossRef]

12. Zamani, M.R.; Aslani, S.; Salmaninejad, A.; Javan, M.R.; Rezaei, N. PD-1/PD-L and autoimmunity: A growing relationship. Cell. Immunol. 2016, 310, 27-41. [CrossRef]

13. Francisco, L.M.; Sage, P.T.; Sharpe, A.H. The PD-1 pathway in tolerance and autoimmunity. Immunol. Rev. 2010, 236, 219-242. [CrossRef]

14. Salama, A.D.; Chitnis, T.; Imitola, J.; Ansari, M.J.; Akiba, H.; Tushima, F.; Azuma, M.; Yagita, H.; Sayegh, M.H.; Khoury, S.J. Critical role of the programmed death-1 (PD-1) pathway in regulation of experimental autoimmune encephalomyelitis. J. Exp. Med. 2003, 198, 71-78. [CrossRef] [PubMed]

15. Huang, C.; Zhu, H.X.; Yao, Y.; Bian, Z.H.; Zheng, Y.J.; Li, L.; Moutsopoulos, H.M.; Gershwin, M.E.; Lian, Z.X. Immune checkpoint molecules. Possible future therapeutic implications in autoimmune diseases. J. Autoimmun. 2019, 104, 102333. [CrossRef] [PubMed]

16. Macek Jilkova, Z.; Decaens, T.; Marlu, A.; Marche, H.; Jouvin-Marche, E.; Marche, P.N. Sex Differences in Spontaneous Degranulation Activity of Intrahepatic Natural Killer Cells during Chronic Hepatitis B: Association with Estradiol Levels. Mediat. Inflamm. 2017, 2017, 3214917. [CrossRef]

17. Macek Jilkova, Z.; Afzal, S.; Marche, H.; Decaens, T.; Sturm, N.; Jouvin-Marche, E.; Huard, B.; Marche, P.N. Progression of fibrosis in patients with chronic viral hepatitis is associated with IL-17(+) neutrophils. Liver Int. Off. J. Int. Assoc. Study Liver 2016, 36, 1116-1124. [CrossRef] [PubMed]

18. Macek Jilkova, Z.; Aspord, C.; Kurma, K.; Granon, A.; Sengel, C.; Sturm, N.; Marche, P.N.; Decaens, T. Immunologic Features of Patients With Advanced Hepatocellular Carcinoma Before and During Sorafenib or Anti-programmed Death-1/Programmed Death-L1 Treatment. Clin. Transl. Gastroenterol. 2019, 10, e00058. [CrossRef]

19. Fugier, E.; Marche, H.; Thelu, M.A.; Macek Jilkova, Z.; Van Campenhout, N.; Dufeu-Duchesne, T.; Leroy, V.; Zarski, J.P.; Sturm, N.; Marche, P.N.; et al. Functions of liver natural killer cells are dependent on the severity of liver inflammation and fibrosis in chronic hepatitis C. PLoS ONE 2014, 9, e95614. [CrossRef] 
20. Cao, J.; Liu, F.X.; Yu, M.X. Expression of programmed death 1 and its ligands in the liver of autoimmune hepatitis C57BL/6 mice. Chin. Med. J. 2009, 122, 1941-1946.

21. Oikawa, T.; Takahashi, H.; Ishikawa, T.; Hokari, A.; Otsuki, N.; Azuma, M.; Zeniya, M.; Tajiri, H. Intrahepatic expression of the co-stimulatory molecules programmed death-1, and its ligands in autoimmune liver disease. Pathol. Int. 2007, 57, 485-492. [CrossRef]

22. Agina, H.A.; Ehsan, N.A.; Abd-Elaziz, T.A.; Abd-Elfatah, G.A.; Said, E.M.; Sira, M.M. Hepatic expression of programmed death-1 (PD-1) and its ligand, PD-L1, in children with autoimmune hepatitis: Relation to treatment response. Clin. Exp. Hepatol. 2019, 5, 256-264. [CrossRef]

23. Aarslev, K.; Dige, A.; Greisen, S.R.; Kreutzfeldt, M.; Jessen, N.; Vilstrup, H.; Deleuran, B.; Grønbæk, H. Soluble programmed death-1 levels are associated with disease activity and treatment response in patients with autoimmune hepatitis. Scand. J. Gastroenterol. 2017, 52, 93-99. [CrossRef] [PubMed]

24. Hadley, T.; Gillespie, S.; Espinoza, H.; Prince, J.; Gronbaek, H.; Chandrakasan, S.; Kuguthasan, S.; Kolachala, V.L.; Gupta, N.A. Soluble PD1 levels are increased with disease activity in paediatric onset autoimmune hepatitis and inflammatory bowel disease. Autoimmunity 2020, 53, 253-260. [CrossRef]

25. Renand, A.; Cervera-Marzal, I.; Gil, L.; Dong, C.; Garcia, A.; Kervagoret, E.; Aublé, H.; Habes, S.; Chevalier, C.; Vavasseur, F.; et al. Integrative molecular profiling of autoreactive CD4 T cells in autoimmune hepatitis. J. Hepatol. 2020. [CrossRef] [PubMed]

26. Gianchecchi, E.; Fierabracci, A. Inhibitory Receptors and Pathways of Lymphocytes: The Role of PD-1 in Treg Development and Their Involvement in Autoimmunity Onset and Cancer Progression. Front. Immunol. 2018, 9, 2374. [CrossRef] [PubMed]

27. Peiseler, M.; Sebode, M.; Franke, B.; Wortmann, F.; Schwinge, D.; Quaas, A.; Baron, U.; Olek, S.; Wiegard, C.; Lohse, A.W.; et al. FOXP3+ regulatory T cells in autoimmune hepatitis are fully functional and not reduced in frequency. J. Hepatol. 2012, 57, 125-132. [CrossRef]

28. Taubert, R.; Hardtke-Wolenski, M.; Noyan, F.; Wilms, A.; Baumann, A.K.; Schlue, J.; Olek, S.; Falk, C.S.; Manns, M.P.; Jaeckel, E. Intrahepatic regulatory $\mathrm{T}$ cells in autoimmune hepatitis are associated with treatment response and depleted with current therapies. J. Hepatol. 2014, 61, 1106-1114. [CrossRef]

29. Wang, C.; Lin, G.H.; McPherson, A.J.; Watts, T.H. Immune regulation by 4-1BB and 4-1BBL: Complexities and challenges. Immunol. Rev. 2009, 229, 192-215. [CrossRef]

30. Bartkowiak, T.; Curran, M.A. 4-1BB Agonists: Multi-Potent Potentiators of Tumor Immunity. Front. Oncol. 2015, 5. [CrossRef]

31. Xia, G.; Wu, S.; Zhang, Y. Anti-4-1BB monoclonal antibodies attenuate concanavalin A-induced immune-mediated liver injury in mice. Exp. Ther. Med. 2016, 12, 1263-1268. [CrossRef] [PubMed]

32. Bartkowiak, T.; Jaiswal, A.R.; Ager, C.R.; Chin, R.; Chen, C.H.; Budhani, P.; Ai, M.; Reilley, M.J.; Sebastian, M.M.; Hong, D.S.; et al. Activation of 4-1BB on Liver Myeloid Cells Triggers Hepatitis via an Interleukin-27-Dependent Pathway. Clin. Cancer Res. Off. J. Am. Assoc. Cancer Res. 2018, 24, 1138-1151. [CrossRef] [PubMed]

33. Liberal, R.; Grant, C.R.; Holder, B.S.; Ma, Y.; Mieli-Vergani, G.; Vergani, D.; Longhi, M.S. The impaired immune regulation of autoimmune hepatitis is linked to a defective galectin-9/tim-3 pathway. Hepatology 2012, 56, 677-686. [CrossRef] [PubMed]

34. Zhao, P.; Wang, P.; Dong, S.; Zhou, Z.; Cao, Y.; Yagita, H.; He, X.; Zheng, S.G.; Fisher, S.J.; Fujinami, R.S.; et al. Depletion of PD-1-positive cells ameliorates autoimmune disease. Nat. Biomed. Eng. 2019, 3, 292-305. [CrossRef] [PubMed] 